\title{
Protection and Utilization of Confucian Temple in Southern Shaanxi from the Perspective of Cultural Heritage
}

\author{
Hongdan Guo \\ School of Literature and Media, Ankang University, Ankang, China \\ Email: 283740382@qq.com
}

How to cite this paper: Guo, H. D. (2020). Protection and Utilization of Confucian Temple in Southern Shaanxi from the Perspective of Cultural Heritage. Open Journal of Social Sciences, 8, 225-237. https://doi.org/10.4236/jss.2020.812017

Received: November 10, 2020

Accepted: December 15, 2020

Published: December 18, 2020

Copyright (อ 2020 by author(s) and Scientific Research Publishing Inc. This work is licensed under the Creative Commons Attribution International License (CC BY 4.0).

http://creativecommons.org/licenses/by/4.0/

\section{(c) (i) Open Access}

\begin{abstract}
As a precious historical and cultural heritage, we should not only pay attention to protection and inheritance, but also fully consider how to develop and utilize the Confucian temples. For this purpose, we carried out field research on the remaining Confucian temples in southern Shaanxi, where social attention is low. After investigation, it was found that: the situation of surviving Confucian temples in southern Shaanxi is different. There are some Confucian temples where the ancient buildings are relatively well preserved, or got seriously damaged but have been restored or rebuilt. There are also some Confucian temples where only a few buildings or a single building exist, or even no physical buildings in the ruins. In terms of the utilization of the existing Confucian temples, except for some Confucian temples, which are now integrated with museums or play their functions as Confucian temples independently, most of the Confucian temples are mainly natural exhibitions, which are semi-open or not open to the outside world, resulting in a low rate of social awareness, not to mention their value and functions. It is hoped that through the development of this project, the Confucian Temple in southern Shaanxi can be brought into the public eye and get higher social attention. We should make this precious historical and cultural heritage revitalized and play its value and function in the modern era when the traditional culture becomes more and more today.
\end{abstract}

\section{Keywords}

Southern Shaanxi, Confucian Temple, Cultural Heritage, Protection, Utilization

\section{Introduction}

\subsection{The Research Background}

Cultural heritage is the outcome of history, including tangible cultural heritage 
and intangible cultural heritage. Tangible cultural heritage refers to "cultural heritage" in the traditional sense. According to the world heritage convention, cultural heritage includes historical relics, historical buildings and human cultural sites. China's cultural heritage is a precious treasure left by our ancestors to future generations. We have the responsibility and obligation to protect, pass on and make good use of it. President Xi Jinping once pointed out: cultural relics carry a splendid civilization, history and culture; they are the precious heritage left to us by our ancestors. The protection of cultural relics benefits both the present and the future. He pointed out in his report to the 19th CPC national congress that: we should strengthen the protection and inheritance of cultural heritage. As the physical building of Confucianism, the Confucius temples are actually cultural relics, but also a valuable material and cultural heritage. We have the responsibility and obligation to protect and pass them on well, and at the same time, we should integrate them with the contemporary society better, display the vitality of the new era, and realize their contemporary value.

\subsection{Research Purpose}

The research results in recent years can be seen from the following aspects: the ritual and sacrificial system of Confucian temple, the construction and decoration of Confucian temple, the change and development of Confucian temple, the protection and development of Confucian temple, and the social function of Confucian temple and so on. From the perspective of research region, the distribution of Confucian temples is not balanced, and even the Confucian temples in some provinces have not aroused widespread concern in the academic circle and society. Compared with Shandong, Sichuan, Hunan, Yunnan and other places, the study of Confucian temple in Shaanxi is relatively weak, especially in southern Shaanxi. The low attention of Confucian temple in southern Shaanxi is not conducive to the inheritance and protection of it, even not conducive to its development and utilization, as well as the display of the value function. Through the development of the project, the paper will help the Confucian temple in southern Shaanxi to enter the public view and gain higher social attention, so as to make it play its value and function in the contemporary era.

\section{The Development of the Confucian Temple}

Literature temple, also known as Confucian temple, is a temple offer sacrifices to Confucius, who was the great thinker and educator in ancient China. "Shiji.Confucius Family" contains: "the later generations changed the room he and his disciple lived into Confucius temple, and put Confucius clothes, hats, lyre, carriage and books into it." (Sima, 2011) "After the death of Confucius, the disciples changed the hall of Confucius into a temple to show their respect for their teacher, and collected the relics used by Confucius during his lifetime, such as clothes, hats and shoes, bed, equipment for sitting and lying, ink-stone, sword, lyre and books, as well as carriage." (Qu, 2011) This is the earliest Confucian 
temple in our country.

In the next two thousand years, especially during the Han Dynasty, Dong Zhongshu put forward the idea of "Ban from hundred philosophers, venerate Confucianism". In order to consolidate their rule, the rulers of each Dynasty vigorously advocated Confucianism. At the same time, Confucian temples were constantly built and repaired all over the country, and the number of Confucian temples increased. "Since the abolishment of imperial examinations and the construction of schools in the late Qing Dynasty, the original functions of sacrificial rites and Confucian teaching have suddenly lost, and the glory of Confucian temple has disappeared. In addition, after the founding of the People's Republic of China, influenced by the movements such as 'criticizing Lin and Confucian' and 'four clean-ups' movement, Confucian temples were not only neglected, but mostly destroyed." (Zhu, Wang, \& Yuan, 2015)

In recent years, with the revival of "sinology fever" and the emphasis on traditional Chinese culture, Confucian culture, which plays a dominant role in traditional culture, has returned to the public eye again, and a great upsurge of research has been started on Confucian temple, the historical building carrying Confucian culture.

\section{The General Situation of Confucian Temple in Southern Shaanxi}

According to the geographical environment and cultural customs, Shaanxi province is divided into three regions: northern Shaanxi, central Shaanxi and southern Shaanxi. In the south of Shaanxi province, the Qinling mountains in the north and the Ba mountains in the south, and the Han river runs through them from west to east. From west to east, southern Shaanxi includes Hanzhong, Ankang, Shangluo three cities. Due to the limitation of geographical environment, the development of southern Shaanxi is not well developed. In the process of high-speed urban modernization, some ancient historical and cultural heritages left in this region are relatively well preserved.

According to the investigation, there are ten Confucian temples in southern Shaanxi. respectively: Hanzhong government Confucian temple, Yang County Confucian temple, Chenggu County Confucian temple, Xixiang County Confucian temple, Ankang Confucian temple, Hanyin Confucian temple, Xunyang Confucian temple, Shangluo Confucian temple, Luo nan Confucian temple, Zhen'an Confucian temple. The relics of these Confucian temples are different from each other, and their conservation status in the local area is different. Now the following will be a detailed summary according to the survey results and interviews.

\section{The Confucian Temple Where Ancient Buildings Are Relatively Well Preserved}

Among the remaining Confucian temples in southern Shaanxi, Hanzhong gov- 
ernment Confucian temple, Xunyang Confucian temple and Luonan Confucian temple are relatively well preserved.

Hanzhong government Confucian temple, "located on Minzhu Street in Hanzhong City, now in the seat of Hanzhong district administration office, was rebuilt in the fifth year of Hongwu in the Ming Dynasty (1372)." (Codification Committee of Regional Chronicles in Hanzhong City, 2005) During the period of war and cultural revolution, the temple suffered a series of damages. There are still Lingxing gate, Panchi, Dacheng hall and other main buildings, attached cultural relics such as stone inscription, stone lion, and building with Buddhism lection. In 2008, the Wenchuan earthquake affected Hanzhong. Lingxing gate was badly damaged in the earthquake, and the Hanzhong municipal government allocated special funds to repair it. In 1986, Hanzhong City people's government announced Hanzhong government Confucian temple was seen as the county-level key cultural relics protection unit. In 2000, Hanzhong City people's government announced it was seen as the municipal key cultural relic protection unit. In 2014, it was listed as a provincial key cultural relic protection unit by Shaanxi provincial people's government.

Xunyang Confucian temple "was built in the fifth year of Hongwu in the Ming Dynasty (1372), and was destroyed by floods in the eighth year of Chenghua in the Ming Dynasty (1472). It is now relocated in the city Gong Jialiang by Do Lin." (Codification Committee of Regional Chronicles in Xunyang Country, 1996) In 1984, the Xunyang County museum was established on the site of the Xunyang Confucian temple, which was immediately put into use by the county museum. At that time, the Confucian temple building, except the Dacheng hall basically preserved the original appearance, the rest of the buildings are dilapidated. The restoration work began in 1984 and lasted 24 years until July 2008. Existing brick carving in screen wall, Lingxing gate, Dacheng gate, Dacheng hall, East-west hip roof and other main buildings, besides there is a Ming Dynasty inscription and three old cypress trees. In 1992, it was announced as the third batch of key cultural relic protection unit in Shaanxi province.

Luonan Confucian temple "was built in the third year of Hongwu in the Ming Dynasty (1370)" (Codification Committee of Regional Chronicles in Shangluo City, 2006). Since the establishment of Confucian temple, the scale pattern has been gradually improved, forming a relatively complete ancient building of Confucius temple. At the end of Chongzhen Ming Dynasty, Luonan Confucian temple was destroyed by military fire, most of the buildings were burnt down. During the reign of emperor Shunzhi, emperor Yongzheng and emperor Qianlong of the Qing Dynasty, the temple underwent three large-scale repairs and reconstruction, thus presenting a mixed style between the Ming and Qing Dynasties. After the founding of the People's Republic of China, two large-scale maintenance and protection works were carried out in the 1980s and 1990s. "During the cultural revolution, the Confucian temple complex was once again destroyed to a great extent," said Chen, director of the museum. [according to the interview materials.] Nowadays, the main buildings of Confucian temple are: 
brick carving in screen wall, Lingxing gate, halberd gate, platform, Dacheng hall, east and west hip roof. Luonan County museum was founded in 1984, relying on ancient buildings of Confucian temple and built, is the relatively complete ancient buildings of central axis style in southern region. Luonan Confucian temple is one of the first county-level key cultural relics protected sites announced in 1983. In 1992, it was announced as the third batch of key cultural relic protection unit in Shaanxi province.

\section{Ancient Buildings of the Confucian Temple Were Seriously Damaged and Have Been Restored or Rebuilt}

The ancient buildings of Ankang Confucian temple, Hanyin Confucian temple and Zhen'an Confucian temple are badly damaged due to historical reasons. Ankang Confucian temple and Hanyin Confucian temple on the old site have been restored and rebuilt, Zhen'an Confucian temple is selected new site to redesign.

Ankang Confucian temple, built in the first year of Zhizheng in the Yuan Dynasty (1341), was originally founded in the old city of Chongdao street (today's Gulou street area). Because the old city of Ankang is close to the Han river, and Ankang Confucian temple is flooded frequently, it was moved to the present site in the 45th year of the reign of emperor Kangxi of Qing Dynasty (1706) (now located in the northeast corner of Ankang new city, close to the first primary school of Ankang city). In the last hundred years, due to the loss of maintenance, the military garrison of the republic of China and the destruction of the cultural revolution, all the ancillary buildings have been demolished, leaving only the Dacheng hall. In 2008, the Ankang government decided to carry out comprehensive maintenance and protection of Dacheng hall of Ankang Confucian temple, and redesigned and built halberd gate, east-west wing-room, platform and others buildings. In 2011, during the implementation of the second phase of the Confucian temple project, the ruins of Confucian temple were partially excavated, and the steps, columns and bricks of the Qing Dynasty were found and protected on site, located in the ruins display window in front of the halberd gate. Ankang Confucian temple was announced as the fourth batch of cultural relics protection unit in Shaanxi province in 2003.

Hanyin Confucian temple "was built in the fifth year of Hongwu in the Ming Dynasty (1372). In 1935, Hanyin middle school was founded, and Confucian temple was used as the school house." (Codification Committee of Regional Chronicles in Hanyin County, 1991) During the cultural revolution, the temple was badly damaged and today only the Dacheng hall remains. In 2005, the school carried out repairs to the Dacheng Hall of the Confucian Temple, restored Panchi and stone bridge, which was funded by the county finance. In 2006, the school raised funds to renovate the surrounding environment of Dacheng hall, laying floors and planting trees. Hanyin Confucian temple, was announced in 1985 as the Hanyin county-level key cultural relic protection unit. In 2008, it was listed as the fifth batch of cultural relics protection unit in Shaanxi province. 
The Zhen'an Confucian temple was built in the seventh year of Ming Zhengde (1512). Confucian temple was originally located in the northwest of the county, now in the Chengguan food bureau yard. In the past, Confucian temple for a group of ancient buildings, facing the street off put up the dismount stone tablet. In the early days of the founding of the People's Republic, the ancient buildings of Confucian temple were demolished one after another. The only remaining building, Dacheng hall of Confucian temple, collapsed seriously due to disrepair. For safety reasons, it was finally demolished in May 2003. Attached cultural relics included three stone tablets and three Ming cypresses. Visiting Zhen'an County museum, curator Li informed that: "there are only two ancient cypress trees left at the old site. Stone carvings were moved to the stele corridor of Xiuping Mountain." [according to the interview materials.] The new site of Confucian temple is located in Zhen'an County museum. In March 2007, the county party committee and the county government decided to rebuild Dacheng hall in the Xiuping park, imitating the architectural style of the Qing Dynasty, consisting of Dacheng hall, wing-room, Confucius statue, front and back square, the corridor of stele and so on. In 1983, Zhen'an Confucian temple was announced as the county-level cultural relics key protection unit.

\section{A Few Buildings or a Single Building of the Confucian Temple}

Yang County Confucian temple, Chenggu County Confucian temple, Xixiang County Confucian temple only have a few buildings or a single building.

Yang County Confucian temple, "located in the middle school of Yang County, was first built during the reign of Tang Tianbao (742-756)." (Codification Committee of Regional Chronicles in Hanzhong City, 2005) "Yang County Confucian temple was destroyed by the war at the end of Yuan Dynasty and reconstructed by Mr.Pan Jinyan who was the county deputy governor at the forth year (1371) of Hongwu period in Ming Dynasty." (Codification Committee of Regional Chronicles in Yang County, 1996) Qing Kangxi years further expansion, after repeated repairs. It is recorded that the Confucian temple at that time was large in scale and complete in form. There only exist dismount stone tablet, Lingxing gate, Dacheng hall, a granite drum stone, a laurel and a cypress-tree. According to the guard who worked in this school for many years: "When building Yang County middle school, the Confucian temple Lingxing gate was used as its school gate, after widening the road, the school gate needs to be rebuilt backward, the old gate (Lingxing gate) was removed to the tomb of Cailun, the new gate is enlarged and rebuilt based on the original Confucian temple Lingxing gate." [according to the interview materials.] Yang County Confucian temple was announced in 1994 as the county-level cultural relics key protection unit.

Chenggu County Confucian temple was built in the second year of Song Chongning (1103), including HongGong and Dacheng hall. It was repaired in Ming and Qing Dynasties, and repaired twice after liberation. During the cultur- 
al revolution, the main buildings of Confucian temple were seriously damaged and a large number of stone tablets were buried. Now only the Dacheng hall remains, which is located in Chenggu normal school affiliated primary school. At present, the only remaining Dacheng hall, due to disrepair, collapse damaged seriously, which is in urgent need of rescue maintenance. Relevant units and departments have not yet carried out overall planning, so the hall has been strictly forbidden to open. In 1981, the Chenggu County people's government announced the Confucian temple Dacheng hall was seen as a cultural relic protection unit. In 1984, the Chenggu County people's government issued a document reaffirming the Confucian temple Dacheng hall was seen as a cultural relic protection unit. In 2008, it was listed as the fifth batch of cultural relics protection unit in Shaanxi province.

Xixiang County Confucian temple "in the city west street. Dacheng hall was built in the second year of Hongwu in the Ming Dynasty (1369)." (Codification Committee of Regional Chronicles in Xixiang County, 1991) The ancient buildings of original Confucian temple were destroyed due to historical reasons, only left the Dacheng hall, brick carving in screen wall and Panchi. Later, due to serious damage to the Dacheng hall, it was demolished in July 1991 with the approval of the competent authorities. Now only brick carving in screen wall and Panchi are located in Xixiang County Chengguan town west street county party committee resident. The remaining stone tablets were moved to Xixiang County cultural center for protection in 2005. Xixiang County Confucian temple was announced in 1985 as the county-level cultural relics key protection unit.

\section{Confucian Temple Which Has Only the Ruins, No Physical Building}

Among the surviving Confucian temples in southern Shaanxi, Shangluo Confucian temple is a special case, which has only ruins, no physical buildings of Confucian temple. Shangluo Confucian temple dates back to the Ming Dynasty and was destroyed during the cultural revolution. "The site of the Confucian temple was once used as a prison after liberation and was destroyed during the cultural revolution." (Shi, Wang, \& Qi, 2016) The former site of Shangluo Confucian temple has been occupied and is now converted into Lianhu park. Confucian temple building only remains Lingxing gate, at the beginning of the liberation, when the construction of Shangluo martyrs cemetery, was moved to the Jinfeng mountain as the martyrs cemetery gate. Lingxing gate was repainted and colourfully painted in 2005, now it is well preserved and has become a major landscape in Shangzhou Jinfeng mountain scenic area.

\section{The Utilization Status of Confucian Temple in Southern Shaanxi}

\subsection{Fully Open Usage}

Xunyang County museum, Luonan County museum and Zhen'an County mu- 
seum are all built on the basis of Confucian temple, so Xunyang Confucian temple, Luonan Confucian temple and Zhen'an Confucian temple are mainly used as museums. "Confucius temple has a unique advantage to be used as a museum because of its historic function, architectural style and cultural heritage value." (Liu, 2009) Museum temple syncretic of Confucian temple, not only play the function of cultural relics collection, display and exhibition, but also play for inheritance and carry forward the excellent traditional culture and native culture, such as the activity of organizing native culture and outstanding historical culture into the campus in the Xunyang Confucian temple, Zhen'an Confucian temple hold classic recitation of the activities. For example, the government Inspirational Award award ceremony and the training program for young leaders were held in Xunyang Confucian temple, are conducive to carry out the ideological and moral education of respecting teachers and cultivating people. Ankang Confucian temple, as the only independent Confucian temple in southern Shaanxi, plays the traditional function of education and sacrificial rites in contemporary society. Ankang Confucian temple holds "Ankang Confucian temple evolution" and "Ankang education history" two exhibitions all the year round, and regularly holds "inspirational award" awarding activities, first writing ceremony and the ceremony of offer sacrifices to Confucius before the examination.

\subsection{Semi-Open Usage}

The so-called semi-open use here refers to those Confucian temples that only serve certain social groups. Such as Yang County Confucian temple, Chenggu County Confucian temple and Hanyin Confucian temple, as the site selection of local schools play a certain educational function. Yang County Confucian temple is now the school site of Yang County middle school, Chenggu County Confucian temple is now the school site of Chenggu normal school affiliated primary school, Hanyin Confucian temple is now the school site of Hanyin County junior high school. "Looking at the history of Confucian temples in China, it can be seen that Confucian temples traditionally had two basic functions: one is to offer sacrifices to Confucius and ancient scholars, and the other is to perform educational functions as an officially recognized school." (Liu, 2011) These schools built on the basis of Confucian temple can be regarded as the continuation of Confucian temple's consistent educational function. Confucian masterwork, such as in the Yang County middle school campus: "The Analects of Confucius", "Three-Character Classic", "Disciple Gauge”, “The Book of Rites University”, “To Encourage Learning”, “On Teaching” can be seen everywhere, which make a strong traditional culture of the campus atmosphere, for students it is a kind of silent influence and education, and encourages students to reflect themselves, strive for excellence.

\subsection{Unexploited}

Among the surviving Confucian temples in southern Shaanxi, Hanzhong gov- 
ernment Confucian temple and Xixiang County Confucian temple have not been opened to the outside. Hanzhong government Confucian temple is now the resident of Hanzhong municipal government, while Xixiang County Confucian temple is the resident of Xixiang County party committee. Due to the particularity of government units, these two Confucian temples are not open to the outside, but mainly displayed by nature. Therefore, the social awareness rate is low, and the Confucian temple does not play its own functions in the contemporary era. Shangluo Confucian temple is a special case among the surviving Confucian temples in southern Shaanxi. Today there are only ruins, no physical buildings. The former site of Shangluo Confucian temple has been occupied and is now converted into Lianhu park.

\section{Some Suggestions on Protection and Utilization of Confucian Temple in Southern Shaanxi}

\subsection{To Formulate Policies for the Protection of Cultural Relics and Implement Protection Units and Commissioners}

During his visit to Beijing, president Xi pointed out that "history and culture are the soul of a city. We should protect the city's historical and cultural heritage as well as we cherish our own lives." The construction of Confucian temple is very old. Man-made factors (damage caused by war, cultural revolution and lack of cultural relic protection awareness of local residents) and natural factors (wind and rain erosion, large temperature difference, biological damage, natural disasters, etc.) often cause partial damage and collapse of Confucian temple buildings. In order to protect and inherit the historical and cultural heritage better, it is necessary to set up special protection agencies, related protection policy, implement the responsibility and measures to protect, and specify the protection commissioners to implement daily inspection, maintenance and security work, accept regularly check and supervision from cultural relics administrative departments and agencies. Such as Xixiang County Confucian temple, in order to strengthen the protection and management of cultural relics, the related workers always have a regular security inspection of the old site, timely and effectively implement the masses of cultural protection staff, and constantly strengthen the safety awareness of education, training, guidance, even focus on strengthening fire prevention, anti-theft, anti-mold, anti-insect protection measures. In March 2011, the "five-level" joint protection system for cultural relics was established, further strengthening the protection and management of cultural relics. This perfect cultural relic protection and management system is worthy of learning by other Confucian temple protection units in southern Shaanxi and even more throughout the country.

\subsection{Establish the Confucian Temple Protection Archives, and Make Timely Registration and Improvement}

Most Confucian temples in southern Shaanxi have established protected arc- 
hives, but they have not been improved in time, such as Hanzhong government Confucian temple and Chenggu County temple. For every damage, repair, inspection, protection and management, a detailed protection management file should be established immediately. The establishment of a complete protection management file is conducive to all the work to be traceable, have records to check, and can be used as the first-hand research data, facilitate the follow-up experience and lessons to be summarized, and also conducive to timely adjustment and formulation of practical protection management policies and measures.

\subsection{The Restoration and Reconstruction of Cultural Heritage Should Follow the Principle of "Restoring the Old as the Old"}

Due to historical factors, natural disasters or man-made damages, the buildings of Confucian temple often appear to be damaged in various degrees. In the process of restoration, the principle of "restoring the old as the old" should be followed and the original appearance of historical sites should not be changed as far as possible. For buildings that no longer exist, they should be designed and rebuilt on their original sites in accordance with the original appearance of cultural relics. This is not only to respect the historical sites, but also to retain the historical connotation and cultural deposits of the ancient sites in the maximum extent. For example, Ankang Confucian temple, because of historical reasons only Dacheng hall remained, in 2008 Ankang city government followed the "restoring the old as the old" principle, made a comprehensive maintenance and protection for Dacheng hall. On the foundation of archaeological excavation, the halberd gate, east-west wing-room and platform were redesigned and rebuilt. Another example is the Confucian temple in Zhen'an. In the early days of the founding of the People's Republic of China, the ancient buildings of the Confucian temple were demolished one after another, only Dacheng hall remained, due to serious disrepair and collapse, it was finally demolished in May 2003. Later, in another site (Xiuping park) for reconstruction, although the Confucian temple is located in a quiet environment, the complex of Confucian temple is full of magnificence, but lack of some simple and elegant atmosphere, to some extent destroyed the Confucian temple's historical and cultural deposits.

\subsection{We Should Make Every Confucian Temple Give Full Play to Its Value and Make the Best Use of Everything}

Hanzhong government Confucian temple and Xixiang County Confucian temple, are now government departments resident. Due to the particularity of government departments, these two relics of Confucian temple are not displayed and open to the public. Panchi and brick carving in screen wall of the relics of Confucian temple in Xixiang, have important local characteristics in architecture and layout. Another example is the Hanzhong government Confucian temple. From the whole region of southern Shaanxi, it is a Confucian temple with relatively well-preserved ancient buildings and relatively more cultural relics left be- 
hind. However, it has always been dominated by natural display, resulting in very low social awareness rate and no value of performance. In the long run, this is not conducive to the Confucian temple's own sustainable development. It is suggested that relevant departments can make overall planning, conduct publicity to raise public attention, and then give play to their social functions; Open regularly for the benefit of the local community as an important window into ancient ruins and traditional culture. If possible, the relevant government departments should move away from the Confucian temple, so that the Confucian temple can give full play to its due value.

\subsection{Modern Urban Space Should Be Integrated with Confucian Temple Architecture}

Confucian temple architecture, as the ancient historical and cultural heritage, its architectural pattern and architectural characteristics, the selection of building materials and colors, are all with a deep historical and cultural background. "The Confucian temple area has experienced a long period of progressive construction development. The remaining buildings in various periods cluster in the visual background of Confucian temple, including traditional dwellings, modern brick and simple buildings, as well as contemporary high-rise buildings, which seriously affect the landscape coordination of Confucian temple site." (Liang, 2017) For example, due to the needs of social development and residents' life, dense modern residential buildings have been built around the Dacheng hall of Confucian temple in Chenggu County. The difference between the newly built buildings and those with traditional features is large, and even the conflict is serious, which directly affects and destroys the historical features. For the buildings around the Confucian temple, "visually, the landscape control protection planning is applied to realize the harmonious transition between the traditional style area and the modern urban space from the three aspects of building height control, color unity and the use of traditional architectural morpheme symbols". (Liang, 2017) The overall planning of the Confucian temple area can make the modern urban space and the Confucian temple area integrated better, which is conducive to maintaining the historical features and charm of ancient buildings.

\subsection{Establish Perfect Service System, Optimize the Traffic Environment of Confucian Temple}

In order to have a better service to local areas and seek diversified development modes, many Confucian temples are exploited and utilized as tourism resources, which requires overall planning to fully reflect local characteristics. "The development of cultural tourism is for the purpose of effective protection and utilization, with a view to achieving a win-win situation of social and economic benefits for Confucian temple, and ultimately realizing the sustainable development of cultural heritage." (Liu, 2011) For example, Xunyang Confucian temple was rated as a "civilized scenic spot" by the CPC Ankang municipal committee and Ankang municipal government in 2011. It has become a beautiful name card 
displaying Xunyang's famous historical and cultural city. Another example the Zhen'an Confucian temple, the new site of rebuilding is located in the Xiuping park. This also aims at building the Confucian temple into a place integrating tourism, leisure, culture and education to benefit the local residents. Since Confucian temple is developed and utilized as a scenic spot, it is necessary to have sound public service facilities, such as routine garbage cans, toilets and seats. Tourist service centers should also be set up to form a complete service system, which is conducive to accelerate the development of Confucian temple as a cultural tourism. Both Xunyang Confucian temple and Zhen'an Confucian temple, as tourist attractions, are located in remote and beautiful mountains, and the traffic is extremely inconvenient, to some extent which has caused the limitation of the beneficiaries, and is not conducive to the effective development of tourism activities. Therefore, relevant departments should carry out overall planning, optimize traffic conditions, consider the opening of special traffic lines, so as to expand the scope of benefits.

After a comprehensive investigation and in-depth analysis of the remaining Confucian temples in southern Shaanxi area, it's found that the status of the remaining Confucian temples is different, especially in the protection and utilization. For the protection of material and cultural heritage, although a certain sense of protection has been established and relevant protection work has been done to a certain extent, there is still a great room for further improvement. According to the current status of the Confucian temple utilization, the efficiency of its utilization is not satisfied, and it fails to make "the best use of everything", the diversified utilization methods need to be further explored.

\section{Conclusion}

As a historical and cultural heritage, Confucian temple should not only be protected and inherited, but also fully be considered how to develop and use to serve the contemporary society. Confucian temple in southern Shaanxi is somewhat limited in the use of heritage. The modern function of Confucian temple is too single, which results in a state of small audience and low social attention. For the historical and cultural heritage, we should fully implement the policy of "protection first, rescue first, rational use, strengthen management", so that it can benefit more people. Therefore, it is necessary to further strengthen the protection of Confucian temple in southern Shaanxi, and at the same time to explore diversified utilization methods, so as to make the temple full of new vitality, so as to serve the contemporary society better and realize its own sustainable development.

\section{Acknowledgements}

Fund project: this paper is a phased research result of the key research project which belongs to the philosophy and social sciences education department of Shaanxi province, "a study on the relics of Confucian temples in southern 
Shaanxi and its social application value" (Project No. 17JZ003).

During the research, thanks to the strong support of Hanzhong City cultural relics tourism bureau, Yang County cultural relics tourism bureau, Chenggu County cultural relics tourism bureau, Xixiang County cultural radio and television cultural relics tourism bureau, Ankang Confucian temple management office, Hanyin County cultural radio tourism bureau, Xunyang County museum, Shangluo City cultural radio bureau, Luonan County museum, Zhen'an County museum, as well as the invited interviewers who provide valuable research materials and the first-hand research materials for the project. Without the help and support of the above related units and individuals, there is no formation of this paper. To this I expressed my deep gratitude for their help.

\section{Conflicts of Interest}

The author declares no conflicts of interest regarding the publication of this paper.

\section{References}

Codification Committee of Regional Chronicles in Hanyin County (1991). Regional Chronicle of Hanyin Country (p. 675). Xi'an: Shaanxi People's Publishing House.

Codification Committee of Regional Chronicles in Hanzhong City (2005). Regional Chronicle of Hanzhong Area (Volume Three, pp. 1655, 1656). Xi'an: Sanqin Press.

Codification Committee of Regional Chronicles in Shangluo City (2006). Regional Chronicle of Shangluo Area (p. 693). Beijing: Fangzhi Press.

Codification Committee of Regional Chronicles in Xixiang County (1991). Regional Chronicle of Xixiang County (p. 545). Xi'an: Shaanxi People's Publishing House.

Codification Committee of Regional Chronicles in Xunyang Country (1996). Regional Chronicle of Xunyang Country (p. 542). Beijing: China Peace Publishing House.

Codification Committee of Regional Chronicles in Yang County (1996). Regional Chronicle of Yang County (p. 673). Xi'an: Sanqin Press.

Liang, H. (2017). Spatial Activation-Integration of Confucian Temple Sites and Modern Cities. Journal of Hefei University of Technology (Social Science Edition), 31, 112-113.

Liu, W. (2009). Study on the Utilization Status of Chinese Confucian Temples in Contemporary Society. Shopping Mall Modernization, No. 17, 16.

Liu, W. (2011). Study on the Utilization Countermeasures of Confucian Temple in Contemporary Society. People's Forum, No. 23, 207.

Qu, Y. J. (2011). Confucian Temple History (p. 11). Beijing: Social Sciences Academic Press.

Shi, Y., Wang, C. K., \& Qi, Y. H. (2016). A Brief Analysis on the Contemporary Value of Confucian Temple in Southern Shaanxi. Outlook on Science and Technology, No. 27, 268.

Sima, Q. (2011). Shiji Confucius Family (p. 1740). Beijing: Zhonghua Book Company.

Zhu, H. Z., Wang, Y. L., \& Yuan, H. S. (2015). Protection Status and Development and Utilization of Confucian Temple in Hebei Province. Journal of Hebei Tourism Vocational College, 20, 18. 